\title{
10 SKILLS FOR EFFECTIVE BUSINESS COMMUNICATION. PRACTICAL STRATEGIES FOR THE WORLD'S GREATEST LEADERS
}

\author{
Jessica Higgins (Author) \\ Tycho Press Publishing House, 2018, 120 pages
}

\section{Anca-Teodora ŞERBAN-OPRESC ${ }^{1}$}

\begin{abstract}
Any instructor of Business English, either with university students, or during training with employees and people from all walks of life wanting to brush and hone their English for Specific Purposes, sooner rather than later, is confronted with the claim that "this is all great, but can you give us some practical advice on how to improve our communication skills in business?"
\end{abstract}

I would consider this to be the main point of appeal for this book - the fact that it actually showcases practical advice on how to deal with all sorts of issues arising in communication acts in the context of business. We all have been through the drills of practicing language, terminology, grammar structures, do's and don'ts in writing up emails in a professional environment. But rendering these into effective communication, updating 'traditional' forms to actual, present business contexts, description of situations that have actual connection to what is happening on a very real level, constitute strong reasons for reading the book. From my instructor perspective, I would always double the academic teaching of business English with a side lecture of practicality in the field of business communication. I once read somewhere that 'communication seems to be the most complex simple' thing and I fully agree.

The author of the book, Jessica Higgins, is a public speaker, strategic consultant and published author in the field of organizational culture. She is chief operating officer of a company dedicated to design and shift culture via management science, communication change, behavior design and influence. Among the company's clients, one reads Microsoft, AT\&T, Pfizer, L'Oreal, U.S. Bank, Babson College, etc. The author's personal input in this book comes from her own experience as consultant in communicating more efficiently, helping people and companies to maximize business and market themselves better.

\footnotetext{
${ }^{1}$ Anca-Teodora Șerban-Oprescu, Bucharest University of Economic Studies, teodora.oprescu@rei.ase.ro
} 
In its Introduction, the book starts with a very simple, yet powerful statement: "effective communication is the key to pretty much everything" (x) and it closely examines the reasons, the ways and the best times to communicate. It is both research and first-hand experience, it is an up-to-date guide of effective communication in business that helps with the art of influencing others, of leading teams, of dealing with difficult personalities and potential conflictual situations at work.

What is clearly stated from the onset of the book and stems from the author's experience is that communication is, at one point or another, a problem for everyone. At the same time, it proves to be a skill - there it can be taught. There are times one fails and times when one gets it right, but the important thing is to practice and get better at it gradually.

In order to reach its stated goal, the book is conceived as a resource for practical business communication skills. It will take through various concepts and tactics in the fields of communication in general, negotiation, non-verbal language, presentation and sales techniques.

Organized into 10 Chapters plus 2 Bonus ones, one can read in the chapters in order or skip to the one or ones that are of particular interest; or come back to certain ones that fit very well a certain situation at work. Each chapter provides a set of skills for mastering an area of communication and practical examples to illustrate, practice and enhance the presented skill. Moreover, at the end, the book provides a chart that includes the skills one needs to develop or master, across an entire array of hypothetical business situations, from hiring someone, to confronting someone in a tough talk, or public speaking. The chapters are easy to follow, each one ends with Key Concepts and an anecdotal stance that has the reader reflect on own experience and put into practice the theory, advice and examples offered.

The book is straightforward, it uses clear, effective language, it offers a lot of examples that are connected to what is going on in real communicational contexts in business and even life. In itself the volume is an example of effective communication. Branding and marketing are the very lifeline of every good business and all great business comes down to great communication - whether it is verbal, written, or artificial intelligence mediated. 